\title{
The BP Algorithm Model of Evaluating Network Learning Behavior
}

\author{
Zhang Yan \\ Teaching Department of Computer and mathematical \\ foundation of Shenyang Normal Universityline \\ Shenyang City ,Liaoning, Chinaline 4: e-mail: \\ Zhangyan_synu@126.com
}

\author{
Zou Lina \\ Teaching Department of Computer and mathematical \\ foundation of Shenyang Normal Universityline \\ Shenyang City ,Liaoning, Chinaline 4: e-mail: \\ zln0781@sina.com
}

\begin{abstract}
The network learning is one new study way, the learning behavior need the real-time monitoring and the effective instruction to through the evaluation in the learning process. The BP algorithm model of evaluating E-Learning behavior selects the learning behavior which affects the study effect in network learning process, has established the network learning behavior evaluating indicator system, and takes the data-in by the second-level target, carries on the network training using MATLAB. In the network training process, the global error assumes the declining trend basically, the restraining effect is good. Through the test indicated that this model may use in evaluating the network learning behavior, and obtains the expectation effect.
\end{abstract}

Keywords- BP algorithm; neural network; network learning; behavior; evaluating

\section{INTRODUCTION}

Network learning behavior is a kind of new things based on new learning concept and learning mode. Compared with the traditional classroom study, network learning is a highly autonomous learning, requires learners has high independent learning ability and self-monitoring ability, can control and adjust their own learning behavior in rich resources environment ${ }^{[1]}$. But, a lot of the investigation and analysis of the studies show that our students' autonomous learning ability generally very low, performance for learning purposes not clear, does not have the effective way to study, can not very well control and adjust their own learning behavior, etc. The individual learning behavior differences can enlarge different learning effect. In network learning mode, the corresponding function of the network learning platform system can capture the differences between individual learning behavior which dispersed in each link, and evaluate the students' learning behavior. The BP neural network can train network model through known data, and applied to predict and evaluate the data of the unknown, which can be rooted in network learning system, and achieving network learning behavior evaluation, Prompt students to change the appropriate study strategy.

\section{NETWORK LEARNING BEHAVIOR EVALUATION MODEL DESIGN}

\section{A. Network learning behavior evaluating indicator}

The network learning behavior is refers to the sum total of the significance construction, the question solution and the socialization interactive activities carried on by the learner in the learning environment which has the rich study resources and the brand-new communication established by computer network under the study goal direction, include dynamic activity in the interactive process and static result. According to this definition, the network learning behavior may divide is 4 appraisal objects, namely learner individual activity, study resources design, study mass sports activity and learning environment establishment and so on. If considering learning environment fixed relatively, mainly realizes the appraisal and the prediction to the different learner's learning behavior, then may simplify the appraisal object to the learner individual activity and learner mass activity. The learner individual activity mainly refers to the behaviors of learner to be clear about study goal, control study progress and adjustment study strategy and so on, the learner mass activity mainly refers to the learner gains support and help from the teacher, the study partner, the discipline expert, the study support system by using the network exchange tool, to deliberate the subject and cooperate to study. Considered the appraisal to the effect produced by learning behavior, increases the learner activity to realize the goal as a appraisal object. The learner activity to realize the goal mainly refers to submitting job, issuing work, publishing the article and so on. Evaluating indicator system in view of the learner activity and the learner sports activity is established as follows (See table 1):

TABLE I . NETWORK LEARNING BEHAVIOR SECOND-LEVEL EVALUATING INDICATOR SYSTEM

\begin{tabular}{|c|l|}
\hline First-level target & \multicolumn{1}{|c|}{ Second-level target } \\
\hline \multirow{4}{*}{$\begin{array}{c}\text { learner media } \\
\text { surface operation } \\
\text { behavior }\end{array}$} & $\begin{array}{l}\text { Browse the teaching guidance } \\
\text { homepage, carry out the study with } \\
\text { the goal (x1) }\end{array}$ \\
\cline { 2 - 2 } & $\begin{array}{l}\text { Browse the teaching guidance } \\
\text { homepage, the frequency is high, the } \\
\text { content is comprehensive (x2) }\end{array}$ \\
\cline { 2 - 2 } $\begin{array}{c}\text { learner activity to } \\
\text { exchange of } \\
\text { information }\end{array}$ & $\begin{array}{l}\text { browse recommended relational } \\
\text { website, quantity are many (x3) }\end{array}$ \\
\hline & $\begin{array}{l}\text { Download the network courseware } \\
\text { and the material provided by platform, } \\
\text { paytention to updated (x4) }\end{array}$ \\
\hline $\begin{array}{l}\text { Participate in study group or learning } \\
\text { group, have the fixed partner and } \\
\text { teachers (x5) }\end{array}$ \\
\cline { 2 - 2 } & $\begin{array}{l}\text { Communications such as inquiry and } \\
\text { reply are active (x6) }\end{array}$ \\
\hline \multirow{3}{*}{$\begin{array}{c}\text { the learner activity } \\
\text { to realize the goal }\end{array}$} & $\begin{array}{l}\text { Demonstrate individual jobs and the } \\
\text { work, the cycle are stable (x7) }\end{array}$ \\
\cline { 2 - 2 } & $\begin{array}{l}\text { Reprint or recommend article or the } \\
\text { work about study, the frequency is }\end{array}$ \\
\hline
\end{tabular}




\begin{tabular}{|l|l|}
\hline & high, the quality is good (x8) \\
\cline { 2 - 2 } & $\begin{array}{l}\text { Issue article about study, the article } \\
\text { click rate is high (x9) }\end{array}$ \\
\hline & $\begin{array}{l}\text { Cooperates to complete the task or the } \\
\text { project, quantity are many, the } \\
\text { function is prominent (x10) }\end{array}$ \\
\hline
\end{tabular}

The network learning behavior's indicator system not only emphasized the influential role of the teaching instruction and teaching resources provided by pedagogue in the learning behavior of student, simultaneously also emphasized the initiative factor of the student studies independently. Under premise of teaching environment relatively fixed, may describe learner's network learning behavior comprehensively. The second-level target's grading value scope is $0 \sim 9$, model measure results can be expressed by outstanding, good, general and bad 4 rank . Concrete assessment method as follows:

- 3 first-level target's measure results has one 0 , then overall measure results for bad;

- 3 first-level target's measure results is not 0 , and appraisal end value $>=0.8$, then overall measure results for outstanding;

- 3 first-level target's measure results is not 0 , and appraisal end value $>=0.6$, then overall measure results for good;

- 3 first-level target's measure results is not 0 , and appraisal end value $>=0.4$, then overall measure results for general;

- 3 first-level target's measure results is not 0 , and appraisal end value $<0.4$, then overall measure results for bad.

\section{B. Design of network learning behavior evaluation model}

Determine number of neurons in input layer ${ }^{[2]}$. According to the network learning behavior evaluating indicator system established, may take 10 second-level targets as the input level neuron, Namely $n=10$;

Determine number of neurons in output layer. The model takes the network learning behavior's measure results as the output of the BP network, namely, $\mathrm{m}=1$;

Determine number of neurons in hide layer. According to empirical formula (1) compute number of neurons in hide layer $^{[3]}, \mathrm{L}=5$ :

$$
l=\frac{3 \sqrt{m n}}{2}
$$

Synthesizes the above conclusion, the appraisal network learning behavior's BP algorithm model is designed 3 layer network structure, namely, input layer with 10 neurons, hide layer with 5 neurons ,output layer with 1 neuron.

\section{NETWORK TRAINING AND RESULT EXAMINATION}

\section{A. Training sample selection}

The training sample takes as the input data set of BP network, will have the vital role regarding the network training, scientific character of the data set selection will decide whether the BP network will be used in forecasting as well as the forecast effect confidence level. In network teaching platform system, carries on the track to student's study condition based on some network curriculum, may obtain student's network learning behavior data, example for browsing homepage record, downloading study material record, respective study group number, content and frequency of exchanging network study information, number of times of submitting job and work, quantity of publishing the article , quantity of cooperation duty and project and so on. The evaluation value of each index is calculated using formula $\mathrm{r}^{+} \mathrm{r}^{*}(\mathrm{f}-\mathrm{s}) / \mathrm{s}$, in which, usually take the median value 5 of second-level targets range $0 \sim 9$, also can be carried out under the appropriate adjustment; $\mathrm{f}$ is the students' actual behavior value of second-level targets measured; $s$ is the average value of student actual behavior of second-level targets measured.

Table 2 data is used to train the BP network model after normalizing and preprocessing, in which, the first 5 columns as input, the sixth column as expectation output of training network. Because primary data's each data item type is independent, thus does not have the unification expression form. In order to satisfy the request of the mapping sigmoid function to input and output data in the BP network, therefore carries on the quantification to the input value, after causing processing, the value falls in $(0,1)$ sector.

TABLE II. TRAINING DATA AFTER PRETREATMENT

\begin{tabular}{|l|l|l|l|l|l|l|}
\hline $\mathbf{X 1}$ & 0.8 & 0.7 & 0.6 & 0.2 & 0.35 & $\ldots$ \\
\hline $\mathbf{X} 2$ & 0.8 & 0.5 & 0.5 & 0.3 & 0.5 & $\ldots$ \\
\hline $\mathbf{X 3}$ & 0.8 & 0.8 & 0.7 & 0.6 & 0.75 & $\ldots$ \\
\hline $\mathbf{X} 4$ & 0.93 & 0.67 & 0.45 & 0.65 & 0.72 & $\ldots$ \\
\hline $\mathbf{X 5}$ & 0.78 & 0.9 & 0.88 & 0.44 & 0.66 & $\ldots$ \\
\hline $\mathbf{X 6}$ & 0.82 & 0.51 & 0.46 & 0.38 & 0.45 & $\ldots$ \\
\hline $\mathbf{X 7}$ & 0.79 & 0.62 & 0.39 & 0.25 & 0.42 & $\ldots$ \\
\hline $\mathbf{X 8}$ & 0.94 & 0.74 & 0.73 & 0.65 & 0.67 & $\ldots$ \\
\hline $\mathbf{X 9}$ & 0.81 & 0.48 & 0.35 & 0.2 & 0.39 & $\ldots$ \\
\hline X10 & 0.63 & 0.39 & 0.3 & 0.1 & 0.33 & $\ldots$ \\
\hline output & 0.8 & 0.6 & 0.4 & 0.2 & 0.4 & $\ldots$ \\
\hline
\end{tabular}

\section{B. Training network}

Data set for the training must contain data to be able to represent all kinds of situations ${ }^{[4]}$. This data set is from running record students' learning and the final grades in the network teaching platform, including 2300 records, takes 2000 records as the network training data, rest of the data used as predictors of data, to confirm the forecast precise degree of the trained network.

Using the matlab toolbox and the auto-adapted gradient descent lr to carry on the model training. The training program code is as follows:

$\mathrm{p}=\{0.8,0.8,0.8,0.93,0.78,0.82,0.79,0.94,0.81,0.63 ;$ $0.6,0.5,0.7,0.45,0.88,0.46,0.39,0.73,0.35,0.3 ; 0.7,0.5$, $0.8,0.67,0.90,0.51,0.62,0.74,0.48,0.39 ; 0.2,0.3,0.6,0.65$, $0.44,0.38,0.25,0.65,0.2,0.1 ; 0.35,0.5,0.75,0.72,0.66$, $0.45,0.42,0.67,0.39,0.33 ; \ldots . .$.$\} ;$

$\%$ input vector

$\mathrm{t}=\{0.8,0.6,0.4,0.2,0.4 \ldots \ldots\}$;

$\%$ expectation output vector

$\mathrm{p}=\mathrm{p}^{\prime} ; \mathrm{t}=\mathrm{t}^{\prime}$;

$\%$ sample matrix transpose 
$\mathrm{n}=10$;

$\%$ number of neurons in hide layer

) ;

net=newff(minmax(p),[n,1],\{‘tansig','purelin'\},'traingda

$\%$ produces a new forward neural network

inputWeights=netIW $\{1,1\}$;

$\%$ weight and threshold value of input layer

inputbias=net.b $\{1\}$;

layerWeights=net.LW $\{2,1\}$;

$\%$ weight and threshold value of hide layer

layerbias $=$ net.b $\{2\}$;

net.trainParam.show $=50$;

$\%$ set the system to display training error change curve

every 50 steps

net.trainParam.lr $=0.05$;

$\%$ set learning rate of the system

net.trainParam.epochs $=5000$;

$\%$ set the maximum number of training

net.trainParam.goal = 1e-4;

$\%$ set learning precision of the system

[net,tr]=train(net,P,T);

$\%$ train BP network

$\mathrm{A}=\operatorname{sim}($ net, $\mathrm{P})$

$\%$ Simulate BP network

$\mathrm{E}=\mathrm{T}-\mathrm{A}$

\% Compute simulation error

$\mathrm{MSE}=\mathrm{mse}(\mathrm{E})$

After 245 trainings, overall expectation error reaches a given range, error change curve in network training process is shown in Figure 1.

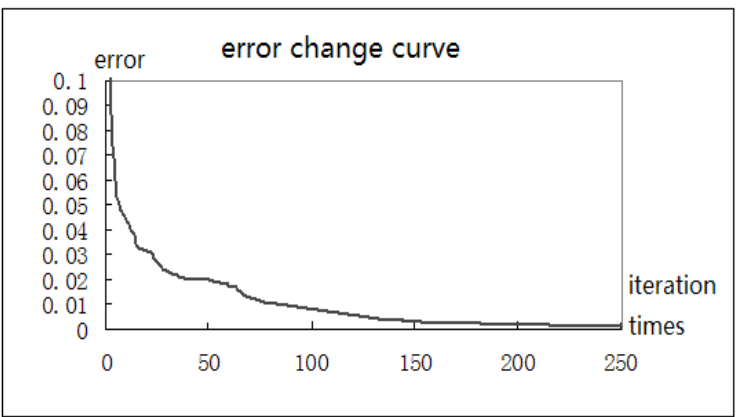

Figure 1. Figure 1. Error Change Curve

It can be seen from error change curve in figure 2, the training process assumes the restraining change, except local convergence speed to be slow, the global error assumes the declining trend basically, the restraining effect is good.

\section{Appraisal and forecast test}

To fit the evaluation of know date with prediction by using the trained network, table 2 has listed the part of fitting data. Because this system needs 4 ranks of the appraisal and the forecasting rather than a specific value, therefore the global error rate is low afte transfer the value to the rank finally.

TABLE III. TEST RESULTS

\begin{tabular}{|c|l|l|}
\hline $\begin{array}{c}\text { network } \\
\text { expectation } \\
\text { output }\end{array}$ & $\begin{array}{c}\text { network actual } \\
\text { output }\end{array}$ & the rank \\
\hline $\mathbf{0 . 8}$ & 0.80012 & outstanding \\
\hline $\mathbf{0 . 4}$ & 0.489 & general \\
\hline $\mathbf{0 . 6}$ & 0.59991 & good \\
\hline $\mathbf{0 . 8}$ & 0.83502 & outstanding \\
\hline $\mathbf{0 . 2}$ & 0.24398 & bad \\
\hline $\mathbf{0 . 6}$ & 0.60315 & good \\
\hline
\end{tabular}

IV. CONCLUSIONS

The network learning behavior appraisal is the complex non-linear problem, the appraisal process has many elements of certainty. The BP neural network has the non-linear mapping function, these can overcome the human factor in the traditional target weight determination, and increase precision of appraises and forecast. The network learning behavior evaluation model may appraises student's learning behavior through the computation to status messages of the student, then provides the personalized guidance to the online learner by network study sufficiency, helps the online learner to adjust the learning behavior to adapt network study pattern as soon as possible ${ }^{[5]}$, and forms the effective network learning behavior custom.

\section{REFERENCES}

[1] Pan Qinghong, Zhao Cengling, “Automatic Feedback Mechanism Research on Network Autonomous Learning Support System,” China Audio-Visual Education, vol. 6, pp. 132-136, 2012

[2] Zhuang Kejun, He Baosun, "Web-based Autonomous Learning Behavior System Framework and Autonomous Learning Behavior Level Tower,” China Audio-visual Education, vol.266, pp.41-45,2009

[3] Ye Bin, Liu Zhigui, “ Network Course Evaluation Study Based on BP Neural Network and the CELTS -22," Microcomputer and applications,vol.20,pp.115-118,2009

[4] Yang Xuemei, Guo Jiayong, "Application of Genetic Algorithm and BP Neural Network in Teaching Management," Computer Knowledge and Technology,vol.(29,pp.8252-8253,2009

[5] Huang Zhen, Huang Yun, “ Model of Learning Design and Research of Network Learning Behavior Analysis Platform” Software Guide, vol.3,pp.195-197,2010 